\title{
Rational Design of Electrocatalytic Interfaces: Cd UPD Mediated Nitrate Reduction on Pd:Au Bimetallic Surfaces
}

Qi Han, ${ }^{+}$Adriel Jebin Jacob Jebaraj, ${ }^{+}$José Solla-Gullón, $^{\circ}$ Juan Feliu, ${ }^{\circ}$ and Daniel Scherson ${ }^{+}$

+ Department of Chemistry, Case Western Reserve University, Cleveland, OH 44106 USA

o Institute of Electrochemistry, University of Alicante, Apdo 99, 03080 Alicante, Spain

\begin{abstract}
Au surfaces modified by Pd electrodeposits have been found to enhance the rates of nitrate electroreduction in acidic aqueous solutions containing $\mathrm{Cd}^{2+}$ over those of the bare Au substrate in the same media. Rather surprisingly, similar electrocatalytic effects were also observed for ensembles of $\mathrm{Au}$ and Pd nanoparticles supported on otherwise inert glassy carbon (GC) surfaces under the same conditions, which suggest that this phenomenon does not originate solely from specific interactions between the two metals. In fact, the overall electrocatalytic activity of GC surfaces decorated with either a fixed number of $\mathrm{Au}$ in one case, or a fixed number of $\mathrm{Pd}$ nanoparticles in the other, displayed much lower activity than GC surfaces covered with a mixture of half of each of them. This unique behavior may be explained by the ability of Pd to reduce $\mathrm{NO}_{2}{ }^{-}$, which is known to be the main reaction product of $\mathrm{NO}_{3}{ }^{-}$reduction on underpotential deposited $\mathrm{Cd}$ on $\mathrm{Au}$.
\end{abstract}

\section{Introduction}

The over-fertilization of agricultural fields is primarily responsible for increases in the concentration of phosphates and nitrogen containing species, particularly nitrate, $\mathrm{NO}_{3}{ }^{-}$, in rivers, lakes and coastal waters. The presence of these nutrients stimulates the growth of aquatic plants, such as algae, which block sunlight and decrease the amount of dissolved oxygen, causing the death of other plants and animals, a phenomenon known as eutrophication. ${ }^{1-3}$ Not surprisingly, considerable efforts are being focused toward addressing this complex phenomenon. As has been discussed in a recent review, ${ }^{4}$ electrochemical denitrification may regarded as among the most promising means of mitigating this problem. However, significant hurdles remain to be overcome for this strategy to become both technologically and economically viable. Although from a strictly thermodynamic viewpoint dinitrogen, $\mathrm{N}_{2}$, would be the most likely, and indeed most desirable product of this multi-electron transfer process, both kinetic and mechanistic factors continue to pose a formidable challenge to both scientists and engineers toward achieving 
this goal. Indeed, numerous electrocatalysts have been examined by research groups worldwide to gain a better understanding of structure-activity relations that could serve as guidelines toward the search of materials displaying the targeted attributes. Based on these studies, ${ }^{4}$ the rate determining step for this process is the two-electron reduction of $\mathrm{NO}_{3}{ }^{-}$to yield nitrite, $\mathrm{NO}_{2}$. which can then undergo subsequent reduction to yield a variety of species. In fact, most electrocatalysts, particularly transition metals, generate ammonia and nitrous oxide, $\mathrm{N}_{2} \mathrm{O}$, a powerful greenhouse gas, as the most common products, a factor that has prompted the search of more complex catalysts. In particular, electrodeposited $\mathrm{Cu}$ on $\mathrm{Pd}$ surfaces has been found to produce $\mathrm{N}_{2}$ with $40 \%$ selectivity at $\mathrm{Cu}$ coverages below $0.2 \mathrm{ML}$ and high overpotentials. ${ }^{5}$ Another promising bimetallic catalyst is $\mathrm{Pt} / \mathrm{Sn},{ }^{6,7}$ which displays $37 \%$ selectivity toward $\mathrm{N}_{2}$ generation during long-term electrolysis. Other bimetallic systems, such as $\mathrm{Pt}-\mathrm{Ge}^{8}$ and $\mathrm{Pt}-\mathrm{Bi}^{9}$ have been reported to yield $\mathrm{NH}_{2} \mathrm{OH}$ and $\mathrm{N}_{2} \mathrm{O}$, respectively. Lastly, a few molecular electrocatalyst, such as metal cyclams, have also been found to enhance $\mathrm{NO}_{3}{ }^{-}$reduction. ${ }^{10}$ Efforts in our laboratories have been focused on the rational design and assembly of bifunctional electrocatalytic interfaces incorporating two electrocatalysts acting in series as a means of improving both the overall activity and specificity of redox processes involving multiple transfer of electrons. This strategy was recently implemented ${ }^{11}$ to promote the reduction of $\mathrm{NO}_{3}{ }^{-}$on $\mathrm{Au}$ nanoparticles (NP) dispersed on the surface of glassy carbon, GC, modified by adsorbed hemin $(\mathrm{Hm})$, an iron porphyrin, in aqueous electrolytes containing $\mathrm{Cd}^{2+}$. This carbonaceous material displays virtually no activity for the reduction of any of the species involved in this reaction, including intermediates and products, and, as such, may be regarded as an ideal support to carry out these studies. As described therein, $\mathrm{Cd}^{2+}(\mathrm{aq})$ undergoes underpotential deposition, UPD, on the $\mathrm{Au}$ surface and promotes reduction of $\mathrm{NO}_{3}{ }^{-}$to predominantly nitrite, $\mathrm{NO}_{2}^{-}$, which is then further reduced by adsorbed $\mathrm{Hm}$, generating, among other products, $\mathrm{NH}_{2} \mathrm{OH}$.

This work represents an extension of this previous study, ${ }^{11}$ in which $\mathrm{Hm}$ has been replaced by $\mathrm{Pd}$ in the form of either electrodeposits on a solid Au disk electrode, or as nanoparticles, NP, dispersed on GC surfaces decorated with Au NP. Impetus for this selection was provided by the much lower overpotential for $\mathrm{NO}_{2}^{-}$reduction of $\mathrm{Pd}$ compared to that of adsorbed $\mathrm{Hm}$, a factor that would lead to overall activities surpassing those found earlier for the Cd(UPD)|Hm system. ${ }^{12}$ As will be shown, the presence of both $\mathrm{Pd}$ and $\mathrm{Au}$ on the electrode surface in solutions containing $\mathrm{Cd}^{2+}$ exhibit much higher activity than those incorporating either $\mathrm{Pd}$ or $\mathrm{Au}$ alone and 
thus consistent with the well-known reduction of $\mathrm{NO}_{3}{ }^{-}$on $\mathrm{Cd}(\mathrm{UPD})$ to $\mathrm{NO}_{2}^{-}$, followed by the reduction of $\mathrm{NO}_{2}{ }^{-}$on $\mathrm{Pd}$ to yield lower oxidation state products. It is interesting to note that catalysts involving $\mathrm{Pd}$ and $\mathrm{Au}$, both as adsorbed layers or as alloys, have been reported to display high activity for a variety of chemical and electrochemical reactions of technical relevance, ${ }^{13}$ including oxygen reduction, ${ }^{14}$ hydrogen peroxide synthesis and reduction, and methanol, ethanol and carbon monoxide oxidation, and, more recently, hydrogen oxidation in alkaline electrolytes, ${ }^{15}$ and, as such, have been the subject of numerous theoretical studies. Several effects have been proposed to explain their unique catalytic activity, including, changes in the electronic band structure, and strain due to atomic rearrangements of surface atoms to mitigate lattice mismatch.

\section{Experimental}

Unless otherwise specified, most measurements were performed in an all-glass, threecompartment cell, filled with deaerated (Ar, Airgas, PP300) $0.1 \mathrm{M} \mathrm{HClO}_{4}$ solutions prepared from ultrapure perchloric acid (Ultrapure, J. T. Baker or OmniTrace Ultra) and ultra-high purity water, UPW, generated by a Barnstead system $(18.2 \mathrm{M} \Omega \mathrm{cm})$. Cadmium perchlorate, $\mathrm{Cd}\left(\mathrm{ClO}_{4}\right)_{2}$ (Sigma-Aldrich, 99.999\%), and sodium nitrate, $\mathrm{NaNO}_{3}$, (Sigma Aldrich, ACS reagent) were used as received. A carbon rod (Alfa Aesar, diameter $6.15 \mathrm{~mm}$ ) was used as counter electrode and either a $\mathrm{Ag} / \mathrm{AgCl}$ (Basi, MF2052) or a standard hydrogen electrode (SHE) as reference electrode. Experiments were carried out with a GC disk electrode (Pine Instruments, disk area, $0.196 \mathrm{~cm}^{2}$ ) or with a polycrystalline $\mathrm{Au} \mid \mathrm{Au}$ ring-disk electrode (Pine Instruments, disk diameter: $0.457 \mathrm{~cm}$; ring inner diameter $0.493 \mathrm{~cm}$; gap, $\mathrm{G}=180 \mu \mathrm{m}$ and ring outer diameter: $0.538 \mathrm{~cm}$, or, correspondingly, disk and ring areas of $0.164 \mathrm{~cm}^{2}$ and $0.037 \mathrm{~cm}^{2}$, respectively, and a collection efficiency, $\mathrm{N}=0.22$ ) or with a Au ring-glassy carbon $(\mathrm{GC})$ disk demountable RRDE (Pine Instruments, disk OD $=5.0 \mathrm{~mm}$; ring $\mathrm{OD}=7.50 \mathrm{~mm}$; ring $\mathrm{ID}=6.50 \mathrm{~mm}$; collection efficiency, $\mathrm{N}=0.25$ ) connected to a rotator (Pine Instruments, Model AFMSRX). A Metrohm Autolab (PGSTAT302N) equipped with a ring module was used to record electrochemical data. Nanoparticles, NPs, of Au and Pd were synthesized and cleaned using a methodology previously described in which an aqueous solution of the corresponding metallic precursor $\left(\mathrm{HAuCl}_{4}\right.$ or $\mathrm{H}_{2} \mathrm{PdCl}_{4}$ ) was reduced with ice-cold and freshly prepared $\mathrm{NaBH}_{4}$ solution in the presence of trisodium citrate. ${ }^{16}$ Glassy carbon surfaces incorporating Au NP and/or Pd NP were prepared by 
first mixing 1 volume of the NP stock suspension as received with 3 volumes of UPW and then delivering $10 \mu \mathrm{L}$ of the dilute NP suspensions to the GC surface using a micropipette, followed by drying under a gentle stream of Ar. These will be denoted hereafter as Au|GC or Pd|GC. GC surfaces containing both Pd NP and Au NP dispersions, $\mathrm{Pd}: \mathrm{Au} \mid \mathrm{GC}$, were prepared by first mixing $500 \mu \mathrm{L}$ of each dilute NP suspension in a vial and, following sonication, delivering $10 \mu \mathrm{L}$ of the mixture on the GC using a micropipette, which was then dried under Ar.

$\mathrm{Pd} / \mathrm{Au}$ microelectrodes, $\mu$-el, were made be encasing either a Pd (Alfa Aesar, $0.1 \mathrm{~mm}$ diameter, 99.99\%) or a $\mathrm{Au}$ (Alfa Aesar, $0.05 \mathrm{~mm}$ diameter, 99.995\%) wire in a glass capillary, following by polishing to expose a disk surface. A copper wire was connected to the end of each $\mu$-el to allow easier handling. For some of the experiments, the two copper wires from each of the microelectrodes were clamped to the same WE alligator to monitor the combined electrochemical response of the assembly. The cell employed for experiments involving $\mu$-el was a polypropylene centrifuge tube (Fisherbrand, $50 \mathrm{~mL}$, STK\# 0644320) with its bottom end cut off to expose a circular hole ca. $5 \mathrm{~mm}$ in diameter. The Au $\mu$-el was inserted into the hole of the cell facing upwards, and a carbon rod (Alfa Aesar, diameter $3.05 \mathrm{~mm}$ ) and a $\mathrm{Ag} \mid \mathrm{AgCl}$ (Basi, MF2052) were used as counter (CE) and reference electrodes (Ref-el), respectively. The Pd $\mu$-el was placed directly above the $\mathrm{Au} \mu$-el aligned along its main axis.

The electrodeposition of Pd on the Au disk was effected by immersing the latter into a $0.1 \mathrm{mM}$ $\mathrm{PdSO}_{4}$ (Sigma Aldrich, 99\%) at $0.75 \mathrm{~V}$ vs Ag/ $\mathrm{AgCl}$. Immediately thereafter, the electrode potential stepped to $\mathrm{E}=0.5 \mathrm{~V}$ vs $\mathrm{Ag} / \mathrm{AgCl}$ for various times so as to achieve for most experiments Pd coverages up to a monolayer. Once the desired coverage was reached, E was stepped back to $1.0 \mathrm{~V}$, the electrode quickly removed from the solution and then rinsed with UPW water to minimize possible contributions due to spontaneous metal deposition. The actual coverage of Pd was estimated by integrating the charge under the transient using the corresponding charge obtained in the absence of $\mathrm{PdSO}_{4}$ in solution. Based on these data about 30 $\mathrm{s}$ were required to deposit a one monolayer equivalent of Pd on $\mathrm{Au}$. Following each experiment with a fixed Pd coverage, the electrode was polished using a fresh pad until the cyclic voltammetry of the Au surface showed no traces of Pd. 


\section{Results and Discussion}

\section{A. Pd modified Au surfaces}

Shown in Panel A, Fig. 1 are linear potential scans recorded at a scan rate $v=10 \mathrm{mV} / \mathrm{s}$ in $0.1 \mathrm{M}$

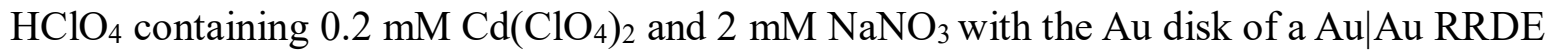
covered with electrodeposited $\mathrm{Pd}$ at the indicated coverages, $\theta_{\mathrm{Pd}}$, under quiescent conditions. As clearly evident from these results, the overall currents for $\mathrm{NO}_{3}{ }^{-}(\mathrm{aq})$ reduction increased with $\theta_{\mathrm{Pd}}$,

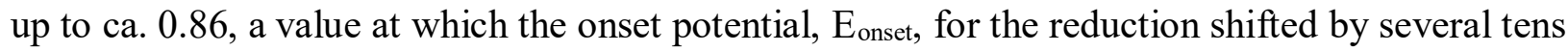
of $\mathrm{mV}$ toward more positive values. As $\theta_{\mathrm{Pd}}$ was increased further, however, the entire polarization curve shifted toward more negative values. Insight into changes in the mechanism associated with the presence of $\mathrm{Pd}$ on the Au surface was obtained by scanning the Au ring at $v=$ $10 \mathrm{mV} / \mathrm{s}$ between 0.4 and $0.95 \mathrm{~V}$, while the $\mathrm{Au}$ disk was polarized at $\mathrm{E}_{\text {disk }}^{\text {hold }}=-0.35 \mathrm{~V}$ vs $\mathrm{Ag} / \mathrm{AgCl}$ under otherwise identical conditions (see Panel B, Fig. 1). As found in earlier publications, ${ }^{17,18}$ the $\mathrm{Cd}(\mathrm{UPD})$ on the $\mathrm{Au}$ disk yields predominantly $\mathrm{NO}_{2}^{-}(\mathrm{aq})$ as the product, for which the onset of oxidation occurs at ca. $0.85 \mathrm{~V}$ vs $\mathrm{Ag} / \mathrm{AgCl}$ (see Panel B, Fig. 1). The ring current, iring, associated with this process decreased as $\theta_{\mathrm{Pd}}$ increased, to yield essentially no response for $\mathrm{Au}$ surfaces fully covered by Pd. On this basis, it can be surmised that the presence of adsorbed Pd can further reduce $\mathrm{NO}_{2}^{-}(\mathrm{aq})$ to a product not detectable by the ring in this potential range. Several explanations can be offered to account for this striking electrocatalytic effect. These include: the formation of $\mathrm{Pd}-\mathrm{Au}$ alloys, changes in the electronic structure of $\mathrm{Pd}$ due to interactions with the underlying $\mathrm{Au}$ substrate, as well as those of $\mathrm{Au}$ neighboring $\mathrm{Pd}$ deposits, and the subsequent reduction of $\mathrm{NO}_{2}^{-}$(aq) generated by the $\mathrm{Cd}(\mathrm{UPD})$ on $\mathrm{Au}$. Attempts to examine some of these possibilities were made by mixing nanoparticles of $\mathrm{Pd}$ and $\mathrm{Au}$ on glassy carbon, GC, a substrate that displays no activity for any of the possible products of this reduction reaction in the potential range of interest, and high overpotential for hydrogen evolution.

\section{B. Metal Nanoparticles supported on Glassy Carbon Electrodes}

\section{Nitrate Reduction.}

Shown in the Panel A, Fig. 2, are dynamic polarization curves collected at $v=10 \mathrm{mV} / \mathrm{s}$ with a $\mathrm{Pd} \mid \mathrm{GC}$ electrode rotating at $\omega=1600 \mathrm{rpm}$ in $0.1 \mathrm{M} \mathrm{HClO}_{4}$ containing $0.2 \mathrm{mM} \mathrm{Cd}\left(\mathrm{ClO}_{4}\right)_{2}$ before (magenta) and after (olive) adding $2 \mathrm{mM} \mathrm{NaNO}_{3}$. The corresponding curve recorded with the 
same electrode in neat $0.1 \mathrm{M} \mathrm{HClO}_{4}$ under the same conditions (see black curve in this figure) displayed features believed to be characteristic of Pd in this electrolyte. As may have been expected, Cd UPD poisons both hydrogen adsorption and absorption on Pd, yielding a rather featureless curve down to the most negative potential limit, except for a very small peak attributed to the stripping of $\mathrm{Cd} \mathrm{UPD}$ centered at ca. $0.05 \mathrm{~V} \mathrm{vs} \mathrm{Ag} \mid \mathrm{AgCl}$ during the scan toward positive potentials. A sizable increase in the current was observed upon subsequent addition of $\mathrm{NO}_{3}^{-}$(aq) for potentials negative to ca. $-0.25 \mathrm{~V}$, revealing, for the first time, the ability of $\mathrm{Cd}(\mathrm{UPD})$ on Pd to catalyze the reaction.

\section{Nitrite Reduction.}

Far higher activities were found for $\mathrm{Pd} \mid \mathrm{GC} \mathrm{RDE}$ for the reduction of $\mathrm{NO}_{2}^{-}(\mathrm{aq})$, as evidenced by dynamic polarization curves recorded at $v=10 \mathrm{mV} / \mathrm{s}$, while rotating at $\omega=400 \mathrm{rpm}$ in $0.1 \mathrm{M}$ $\mathrm{HClO}_{4}$ containing $2 \mathrm{mM} \mathrm{NaNO}_{2}$ before (red in Panel B, Fig 2) and after (blue in the same panel) addition of $1 \mathrm{mM} \mathrm{Cd}\left(\mathrm{ClO}_{4}\right)_{2}$. As before, the black curve was collected under same conditions in neat $0.1 \mathrm{M} \mathrm{HClO}_{4}$. In rather recent studies, ${ }^{19}$ bimetallic $\mathrm{Pd} / \mathrm{Au}$ specimens in the form of nanoparticles, were found to display activity toward the reduction of nitrite in buffered hydrogen-purged aqueous electrolytes with close to $100 \%$ selectivity for dinitrogen generation. The actual activity was found to depend on the amount of Pd in the bimetallic particles, increasing from zero for pure $\mathrm{Au}$, up to a maximum at $80 \% \mathrm{Pd}$ and then decreasing thereafter. As pointed out by the authors, the use of a buffer was required to eliminate a $\mathrm{pH}$ increase during nitrite reduction. These bimetallic particles were found to retain their activity in solutions containing chloride at levels comparable to those found in groundwater and, as such, were regarded as good candidates for practical water remediation. It should be stressed that the effects

observed are in fact expected based on the electrochemical results observed in our experiments, where the presence of hydrogen in solution raises the Fermi level of the $\mathrm{Pd} / \mathrm{Au}$ NP to a level sufficient to inject electrons into $\mathrm{NO}_{3}^{-}(\mathrm{aq})$ leading to its reduction and the concomitant oxidation of $\mathrm{H}_{2}$ in solution.

Shown in the Insert, Fig. 3 are cyclic voltammograms recorded with the Au|GC (magenta), $\mathrm{Pd} \mid \mathrm{GC}$ (black) and $\mathrm{Pd}: \mathrm{Au} \mid \mathrm{GC}$ (blue) electrodes in neat $0.1 \mathrm{M} \mathrm{HClO}_{4}$, displaying features believed to be characteristic of the metals involved. Integration of the characteristic reduction peaks in blue in the Insert, were found to be approximately half of those for either $\mathrm{Au} \mid \mathrm{GC}$ or $\mathrm{Pd} \mid \mathrm{GC}$ (see magenta and black curves in the same Insert), and thus consistent with the relative 
amounts of each of the NP in the Pd:Au|GC electrode. Cursory inspection of the data in Panel A, Fig. 3 reveals much higher activity for the $\mathrm{Pd}: \mathrm{Au} \mid \mathrm{GC}$ than for specimens involving a single metal $\mathrm{NP}$, even though their actual number of clusters of each individual metal was reduced by half. The same overall trend was found for measurements performed under forced convection, as shown in Panel B in this figure.

The amount of $\mathrm{NO}_{2}^{-}(\mathrm{aq})$ generated by these specimens was monitored by the same method as that employed for the Pd-modified Au surfaces in Panel B in Fig. 1, where, in this case (see Panel C, Fig. 3), the disk, rotating at $\omega=400 \mathrm{rpm}$, was polarized at $\mathrm{E}_{\text {disk }}^{\text {hold }}=-0.4 \mathrm{~V}$, while scanning $E_{\text {ring }}$ at $v=10 \mathrm{mV} / \mathrm{s}$ between 0.4 and $0.95 \mathrm{~V}$. In direct analogy with the results found for the Pd-modified Au surfaces, the amount of $\mathrm{NO}_{2}^{-}(\mathrm{aq})$ detected decreased for the Pd:Au|GC electrode, perhaps rather fortuitously by one half compared to $\mathrm{Au} \mid \mathrm{GC}$, and was negligible for $\mathrm{Pd} \mid \mathrm{GC}$. Given the much higher activity for $\mathrm{NO}_{3}{ }^{-}(\mathrm{aq})$ reduction found for the $\mathrm{Pd}: \mathrm{Au} \mid \mathrm{GC}$ specimen, it can be concluded that at least a significant fraction of $\mathrm{NO}_{3}^{-}$(aq) reduction proceeds via a series mechanism that involves $\mathrm{NO}_{2}^{-}(\mathrm{aq})$ as an intermediate, which is further reduced on $\mathrm{Pd}$ to yield products of lower oxidation state.

\section{C. $\mu$-electrode Measurements}

Further insight into these issues was gained from experiments involving a Pd and a Au disk $\mu$ electrodes facing one another immersed in $0.1 \mathrm{M} \mathrm{HClO}_{4}$ containing $1 \mathrm{mM} \mathrm{Cd}\left(\mathrm{ClO}_{4}\right)_{2}$ and $2 \mathrm{mM}$ $\mathrm{NaNO}_{3}$. This tactic is aimed at avoiding any physical contact between the two metals and thus eliminate any interactions that could alter their intrinsic electrocatalytic activities. For these measurements, the two microelectrodes were connected to the working electrode input of the potentiostat, and the current monitored as a function of the distance, $\delta$, between the two disks. Shown in Fig. 4, are current vs time transients recorded for the combined $\mathrm{Pd} / \mathrm{Au}$ microelectrodes in the specified electrolyte following a potential step from about $0.4 \mathrm{~V}$, a value at which no reaction occurs to $\mathrm{E}_{\text {hold }}=-0.4 \mathrm{~V}$ vs $\mathrm{Ag} / \mathrm{AgCl}$, for three different values of $\delta$, as specified. As indicated, the steady state currents were found to increase as $\delta$ decreased. This finding is consistent with the view that the activity can be at least in part be ascribed to the two electrocatalysts acting in series.

\section{Concluding Remarks}

The results of this investigation have provided evidence that Au surfaces modified by $\mathrm{Pd}$ electrodeposits display activities for nitrate reduction in acidic aqueous solutions containing $\mathrm{Cd}^{2+}$ 
much higher than those found for the bare Au substrate in the same media. These same effects were also found for ensembles of $\mathrm{Au}$ and Pd nanoparticles supported on otherwise inert glassy carbon (GC) surfaces under the same conditions, where the possibility of intimate contact between the two metals would be greatly diminished. On this basis, one may conclude that this phenomenon does not originate solely from specific Au-Pd interactions. Rather strikingly, the overall electrocatalytic activity of GC surfaces decorated with either a fixed number of Au in one case, or a fixed number of Pd nanoparticles in the other, displayed much lower activity than GC surfaces covered with a mixture of half of each of them. This unique behavior may be explained in part by the ability of $\mathrm{Pd}$ to reduce $\mathrm{NO}_{2}{ }^{-}$, which is known to be the main reaction product of $\mathrm{NO}_{3}{ }^{-}$reduction on underpotential deposited $\mathrm{Cd}$ on $\mathrm{Au}$.

\section{Acknowledgments}

This work was supported by a grant from NSF, CHE-1412060.

\section{References}

1. D. V. Schindler, John R, Over fertilization of the World's Freshwaters and estuaries, University of Alberta Press (2004).

2. W. Werner, in Ullmann's Encyclopedia of Industrial Chemistry, Wiley-VCH Verlag $\mathrm{GmbH} \& \mathrm{Co} . \mathrm{KGaA}(2000)$.

3. M. Callisto, J. Molozzi and J. L. E. Barbosa, in Eutrophication: Causes, Consequences and Control, A. A. Ansari and S. S. Gill Editors, p. 55, Springer Netherlands (2014).

4. M. Duca and M. T. M. Koper, Energy Environ. Sci., 5, 9726 (2012).

5. A. C. A. de Vooys, R. A. van Santen and J. A. R. van Veen, Journal of Molecular Catalysis A: Chemical, 154, 203 (2000).

6. K. Tada and K. Shimazu, Journal of Electroanalytical Chemistry, 577, 303 (2005).

7. J. Yang, M. Duca, K. J. P. Schouten and M. T. M. Koper, Journal of Electroanalytical Chemistry, 662, 87 (2011).

8. G. E. Dima, V. Rosca and M. T. M. Koper, Journal of Electroanalytical Chemistry, 599, 167 (2007).

9. M. C. Figueiredo, J. Souza-Garcia, V. Climent and J. M. Feliu, Electrochemistry Communications, 11, 1760 (2009).

10. I. Taniguchi, N. Nakashima, K. Matsushita and K. Yasukouchi, Journal of Electroanalytical Chemistry and Interfacial Electrochemistry, 224, 199 (1987).

11. Y. Chen, H. Zhu, M. Rasmussen and D. Scherson, J. Phys. Chem. Lett., 1, 1907 (2010).

12. K. Nakata, Y. Doi, S. Kubota and K. Shimazu, J. Electroanal. Chem., 647, 187 (2010).

13. E. Pizzutilo, S. J. Freakley, S. Geiger, C. Baldizzone, A. Mingers, G. J. Hutchings, K. J. J. Mayrhofer and S. Cherevko, Catal. Sci. Technol., 7, 1848 (2017).

14. M. H. Shao, T. Huang, P. Liu, J. Zhang, K. Sasaki, M. B. Vukmirovic and R. R. Adzic, Langmuir, 22, 10409 (2006).

15. S. Henning, J. Herranz and H. A. Gasteiger, J. Electrochem. Soc., 162, F178 (2015).

16. C. M. Sanchez-Sanchez, F. J. Vidal-Iglesias, J. Solla-Gullon, V. Montiel, A. Aldaz, J. M. 
Feliu and E. Herrero, Electrochim. Acta, 55, 8252 (2010).

17. H. Huang, M. Zhao, X. Xing, I. T. Bae and D. Scherson, J. Electroanal. Chem. Interfacial Electrochem., 293, 279 (1990).

18. X. Xing, D. A. Scherson and C. Mak, J. Electrochem. Soc., 137, 2166 (1990).

19. H. Qian, Z. Zhao, J. C. Velazquez, L. A. Pretzer, K. N. Heck and M. S. Wong, Nanoscale, 6, 358 (2014). 

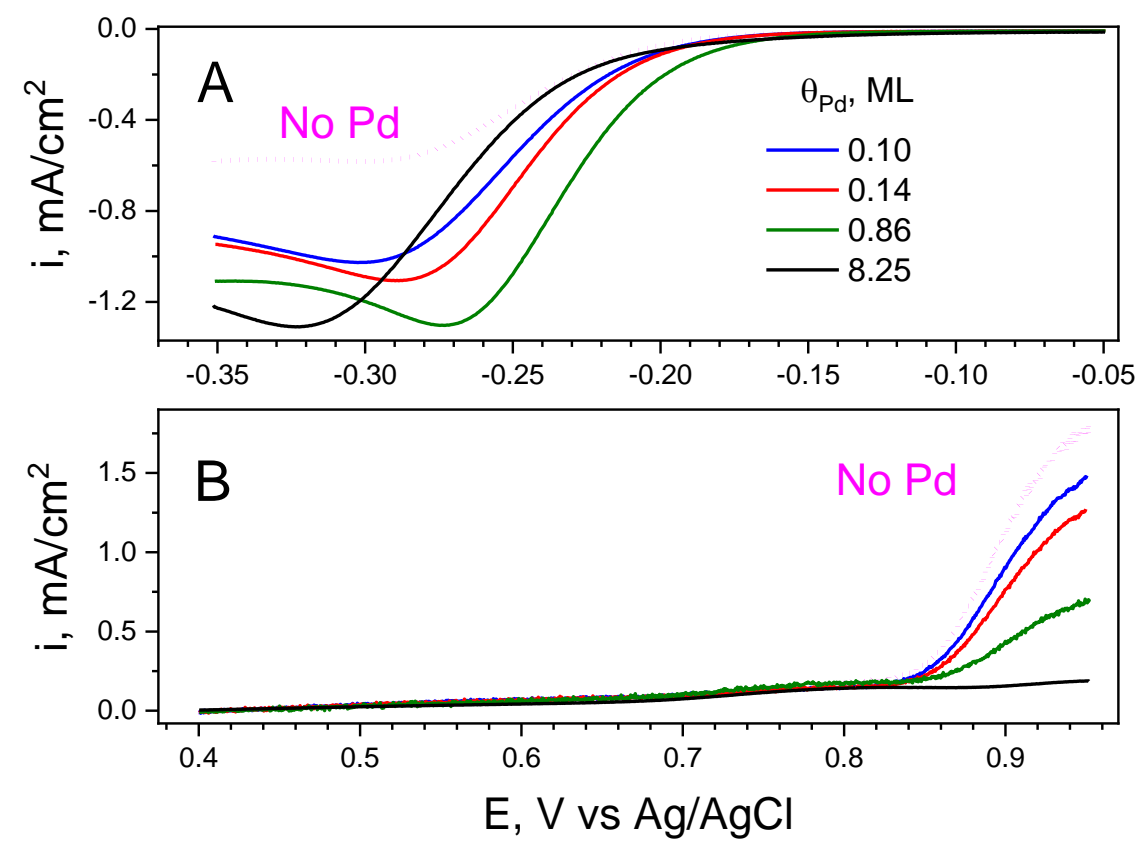

Figure 1. Panel A. Linear potential scans $(v=10 \mathrm{mV} / \mathrm{s})$ recorded toward negative potentials for the $\mathrm{Au}$ disk of the $\mathrm{Au} \mid \mathrm{Au} \mathrm{RRDE}$ (magenta) covered with different $\theta_{\mathrm{Pd}}$ in $0.1 \mathrm{M} \mathrm{HClO}_{4}$ containing $0.2 \mathrm{mM} \mathrm{Cd}\left(\mathrm{ClO}_{4}\right)_{2}$ and $2 \mathrm{mM} \mathrm{NaNO}_{3}$ under quiescent conditions. Panel B. Ring currents, $\mathrm{i}_{\text {ring }}$, recorded with the Pd-modified $\mathrm{Au}$ disk of the RRDE polarized at $\mathrm{E}_{\text {disk }}^{\text {hold }}=-0.35 \mathrm{~V}$ vs $\mathrm{Ag} / \mathrm{AgCl}$, rotating at $\omega=400 \mathrm{rpm}$, while scanning the potential of the Au ring at $v=10 \mathrm{mV} / \mathrm{s}$ between 0.4 and $0.95 \mathrm{~V}$, for the values of $\theta_{\mathrm{Pd}}$ specified. 


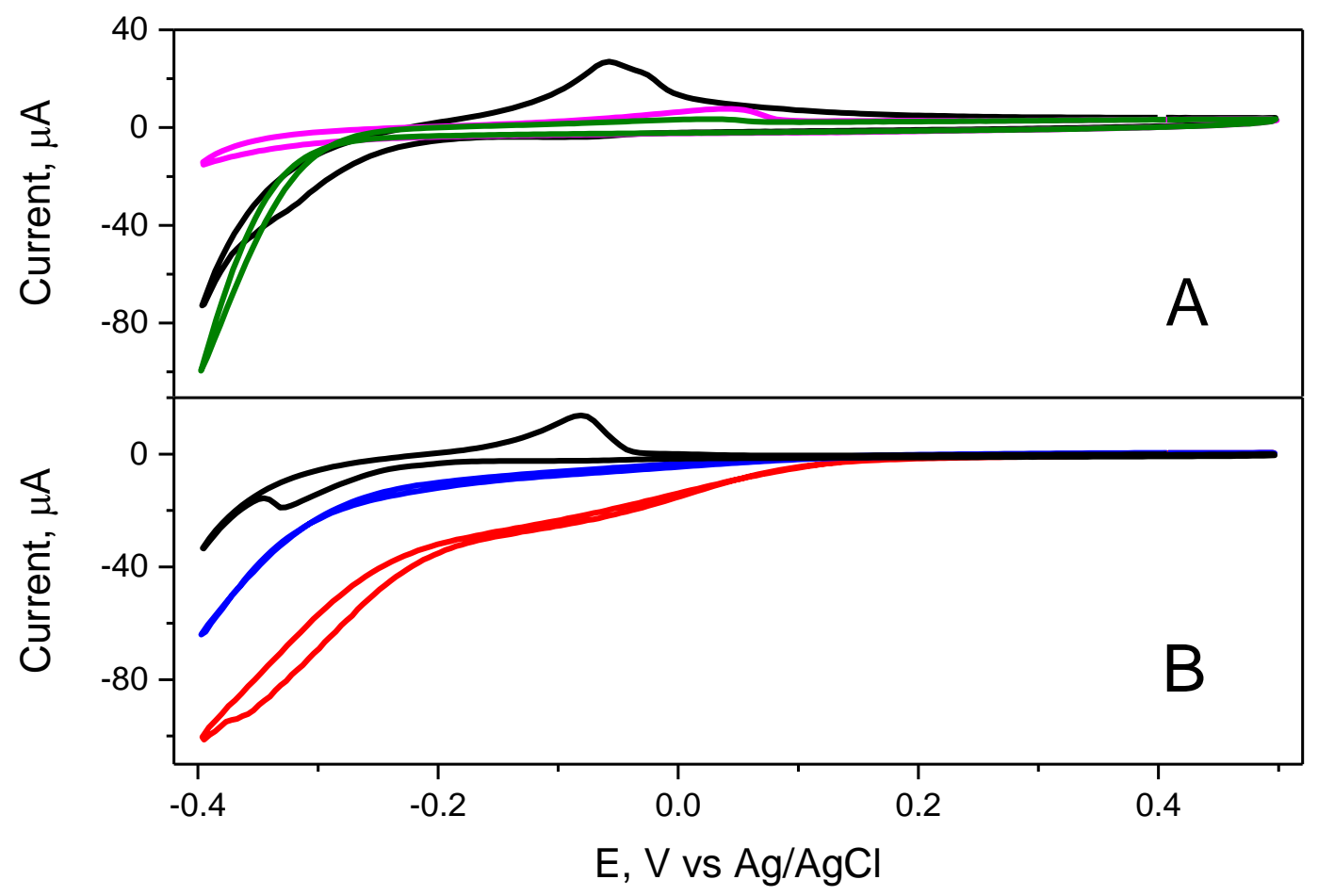

Figure 2. Panel A. Dynamic polarization curves $(v=10 \mathrm{mV} / \mathrm{s})$ collected with a $\mathrm{Pd} \mid \mathrm{GC} \mathrm{RDE}$ rotating at $\omega=1600 \mathrm{rpm}$ in $0.1 \mathrm{M} \mathrm{HClO}_{4}$ containing $0.2 \mathrm{mM} \mathrm{Cd}\left(\mathrm{ClO}_{4}\right)_{2}$, before (magenta) and after adding $2 \mathrm{mM} \mathrm{NaNO}_{3}$ (olive). The black curve was obtained with the same electrode in neat $0.1 \mathrm{M} \mathrm{HClO}_{4}$ under the same conditions. Panel B. Dynamic polarization curves $(v=10 \mathrm{mV} / \mathrm{s})$ recorded with the $\mathrm{Pd} \mid \mathrm{GC} \mathrm{RDE}$ at $\omega=400 \mathrm{rpm}$ in $0.1 \mathrm{M} \mathrm{HClO}_{4}$ containing $2 \mathrm{mM} \mathrm{NaNO}_{2}$ before (red) and after (blue) the addition of $1 \mathrm{mM} \mathrm{Cd}\left(\mathrm{ClO}_{4}\right)_{2}$. The black curve was collected under the same conditions in neat $0.1 \mathrm{M} \mathrm{HClO}_{4}$. 

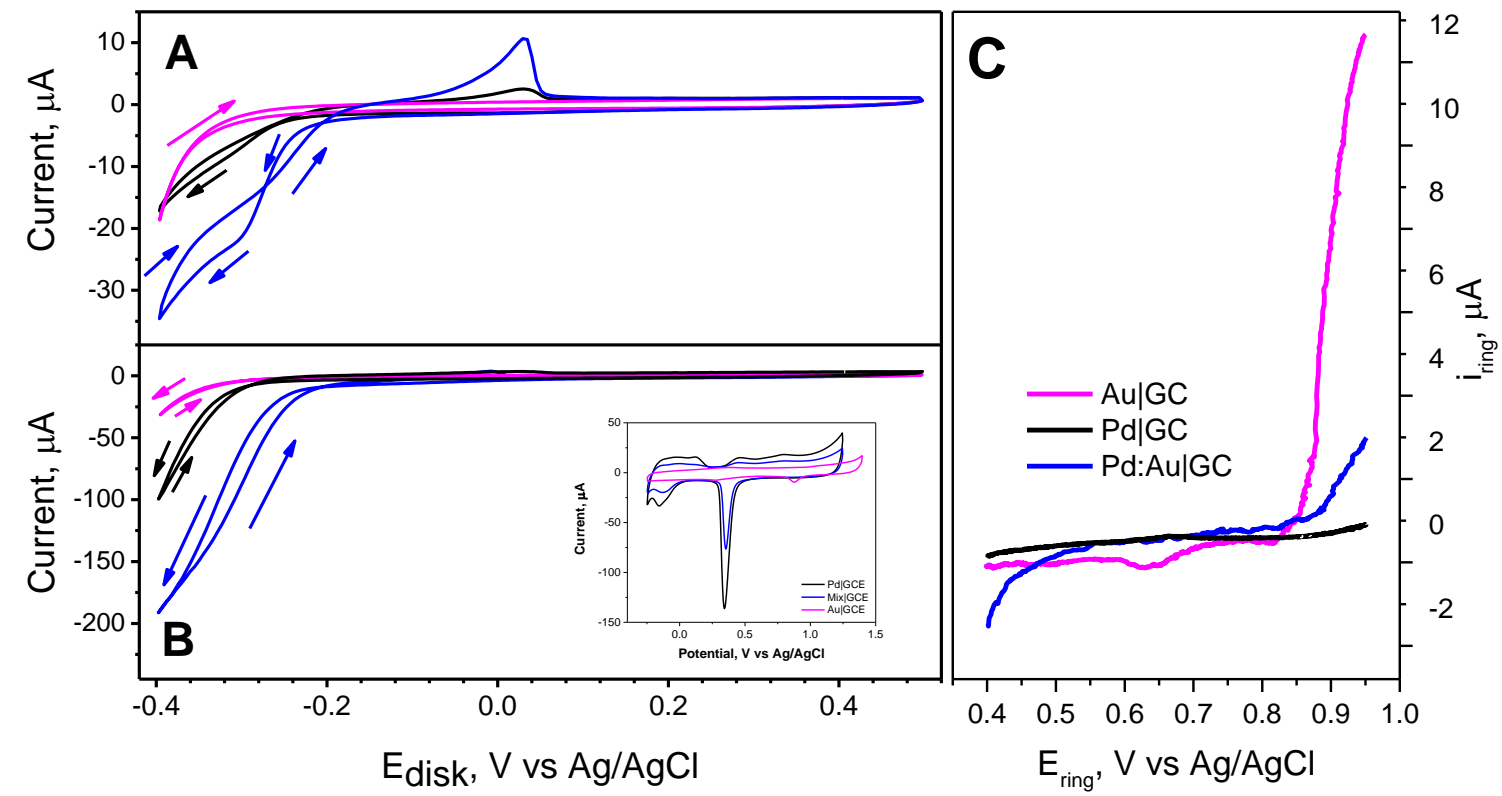

Figure 3. Panel A. Cyclic voltammograms recorded at $v=10 \mathrm{mV} / \mathrm{s}$ with the $\mathrm{Au} / \mathrm{GC}$ (magenta), $\mathrm{Pd} \mid \mathrm{GC}$ (black) and a $\mathrm{Pd}: \mathrm{Au} \mid \mathrm{GC}$ (blue) electrodes in $0.1 \mathrm{M} \mathrm{HClO}_{4}$ containing $1 \mathrm{mM} \mathrm{Cd}\left(\mathrm{ClO}_{4}\right)_{2}$ and $2 \mathrm{mM} \mathrm{NaNO}_{3}$, under quiescent conditions. Panel B. Dynamic polarization curves $(v=10$ $\mathrm{mV} / \mathrm{s}$ ) recorded for the same specimens in the same electrolytes at $\omega=1600 \mathrm{rpm}$. Panel C. Plot of $i_{\text {ring }}$ recorded with the Au ring- $\mathrm{GC}$ disk at $\omega=400 \mathrm{rpm}$ in $0.1 \mathrm{M} \mathrm{HClO}_{4}$ containing $1 \mathrm{mM}$ $\mathrm{Cd}\left(\mathrm{ClO}_{4}\right)_{2}$ and $2 \mathrm{mM} \mathrm{NaNO}_{3}$ for $\mathrm{Au} \mid \mathrm{GC}$ (magenta), Pd|GC (black) and $\mathrm{Pd}: \mathrm{Au} \mid \mathrm{GC}$ (blue) when disk electrodes polarized at $\mathrm{E}_{\text {disk }}^{\text {hold }}=-0.4 \mathrm{~V}$ vs $\mathrm{Ag} / \mathrm{AgCl}$, while scanning $\mathrm{E}_{\text {ring }}$ at $v=10 \mathrm{mV} / \mathrm{s}$ between 0.4 and $0.95 \mathrm{~V}$. Insert: Cyclic voltammogram recorded at $v=100 \mathrm{mV} / \mathrm{s}$ with the same specimens in neat, quiescent $0.1 \mathrm{M} \mathrm{HClO}_{4}$. 


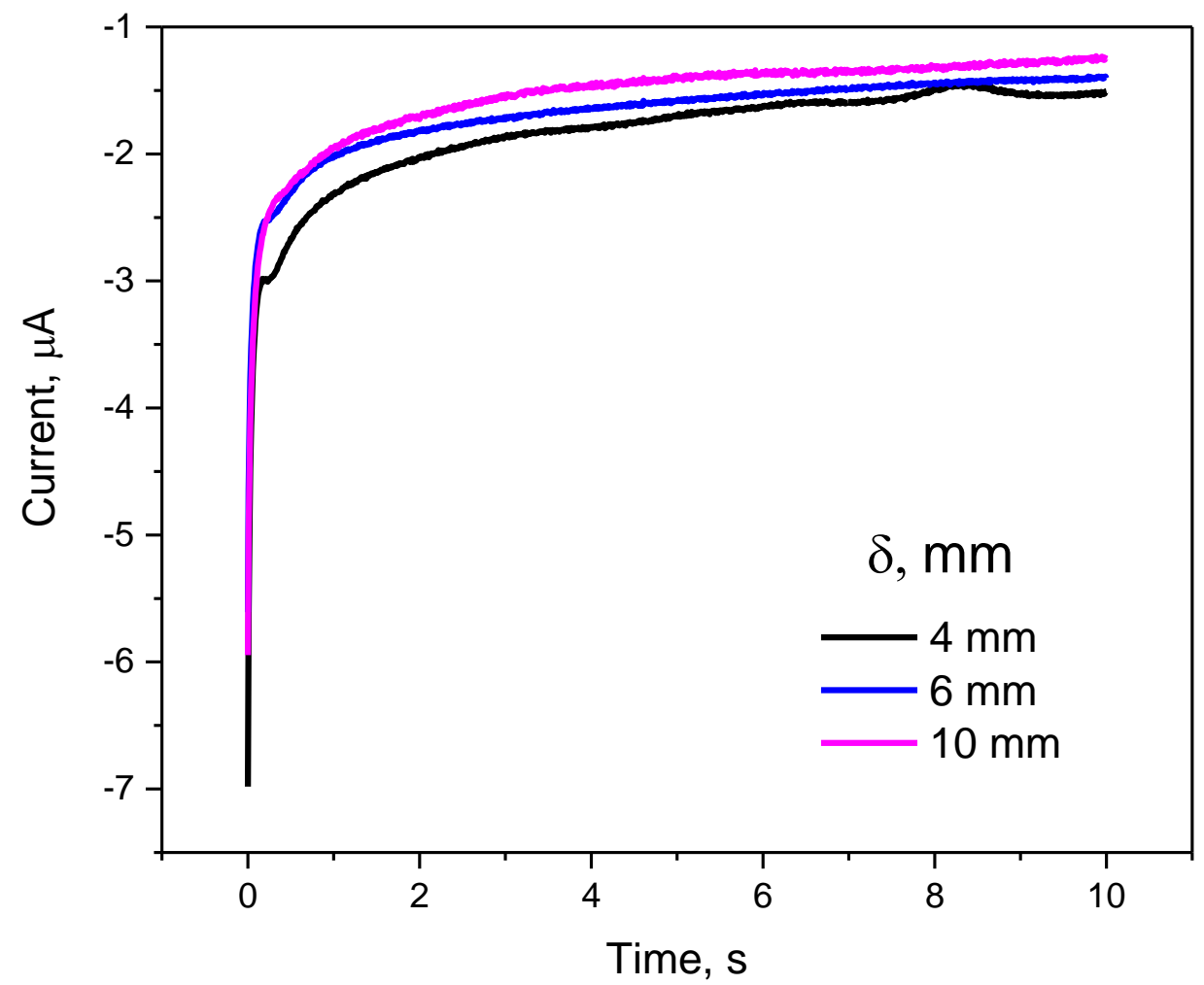

Figure 4. Total currents recorded passing through $\mathrm{Pd}$ and $\mathrm{Au}$ microelectrodes in $0.1 \mathrm{M} \mathrm{HClO}_{4}$ with $1 \mathrm{mM} \mathrm{Cd}\left(\mathrm{ClO}_{4}\right)_{2}$ and $2 \mathrm{mM} \mathrm{NaNO}_{3}$ for $\mathrm{E}_{\text {hold }}=-0.4 \mathrm{~V} \mathrm{vs} \mathrm{Ag} / \mathrm{AgCl}$, for three different values of $\delta$, as specified. 